\title{
New polyene macrolide family produced by submerged culture of Streptomyces durmitorensis
}

\author{
Eva Stodůlková ${ }^{1}$, Marek Kuzma $^{1}$, Ivana Bratic Hench $^{2}$, Jan Černý ${ }^{3}$, Jarmila Králová ${ }^{4}$, Petr Novák ${ }^{1}$, \\ Milada Chudíčková ${ }^{1}$, Miloje Savic ${ }^{2}$, Lidija Djokic ${ }^{2}$, Branka Vasiljevic ${ }^{2}$ and Miroslav Flieger ${ }^{1}$
}

A new polyene macrolide family, closely related to the pentaene macrolide antibiotic roflamycoin, was isolated from the both fermentation broth and biomass of Streptomyces durmitorensis wild-type strain MS405. The main compound was identified by NMR and Fourier transform ion cyclotron resonance mass spectrometry as 32,33-didehydroroflamycoin (1; DDHR). Additional four structurally related compounds were determined solely by MS analysis. DDHR induces cell death by apoptosis in various cancer cell lines as demonstrated by DNA fragmentation. Striking feature of DDHR is its internal fluorescence allowing visualization of labeled plasma membranes and internal membrane structures.

The Journal of Antibiotics (2011) 64, 717-722; doi:10.1038/ja.2011.81; published online 14 September 2011

Keywords: apoptosis; FTMS; NMR; polyene macrolide; Streptomyces durmitorensis; structure elucidation

\section{INTRODUCTION}

The main stream of discovery of new bioactive compounds is now concentrated on marine macro and microorganisms and is likely to provide thousands of new compounds with a wide range of bioactivities. ${ }^{1-3}$ Actinomycetes in particular Streptomyces species still represent almost inexhaustible source of new compounds with antibiotic, antifungal and other important biological activities. ${ }^{4}$

Polyketides a highly diverse group of natural products are currently represented with over 10000 members so far identified..$^{5}$ The most important subgroup of this family is represented by polyene macrolide antibiotics counting over 200 known compounds isolated and characterized since 1950. Most of these compounds are produced by soil actinomycetes belonging to the Gram-positive bacteria of the genus Streptomyces. ${ }^{6}$ These natural products have a polyene ranging from three to seven double bonds in length. Only few compounds of this family represent clinically important drugs, most probably because of their high toxicity causing serious side effects as renal failure, hypokalemia and thrombophlebitis. ${ }^{4}$ Among those with clinical usage are rapamycin (triene), ${ }^{7}$ nystatins (tetraenes), ${ }^{8}$ filipins (pentaenes) ${ }^{9}$ and amphotericin B (heptaene). ${ }^{10}$ In recent years there has been a considerable progress in the genetic analysis and manipulation of producing strains, which led to engineered biosynthesis of several new polyenes used for detailed studies of structure-activity relationships. ${ }^{11,12}$ This strategy together with isolation and characterization of new compounds produced by different microorganisms ${ }^{13-15}$ could result in potential applications in therapy of cancer.
Roflamycoin, pentaene macrolide antibiotic originally called flavomycoin was isolated over 20 years ago from Streptomyces roseoflavus JA 5068. ${ }^{16}$ The flat structure was reported in 1981 by Schlegel, ${ }^{17}$ whereas the absolute configuration and total synthesis was elucidated by Rychnovsky group. ${ }^{18,19}$ Roflamycoin is an unusual member of the polyene macrolide antibiotics that has been shown to form welldefined ion channels. ${ }^{20}$ In addition to oxo-polyene macrolides, mycosamine-containing polyene macrolide antibiotics such as nystatin and amphotericin $\mathrm{B}^{21}$ also possess well-characterized ion-channel-forming properties. Despite their toxicity and side effects ${ }^{22}$ they have been used for $>40$ years as the most effective antifungal agents. For this reason, the finding of new antifungal drugs has become an exciting challenge.

In this work the submerged fermentation, isolation, purification and structure determination of 32,33-didehydroroflamycoin (1, DDHR), a member of new macrolide family produced by Streptomyces durmitorensis MS405 is described. Its biological activity was tested on HeLa cells and different carcinoma mouse and human cell lines.

\section{MATERIALS AND METHODS}

General experimental procedures

UV spectra were monitored in methanol in the range of $190-700 \mathrm{~nm}$ using Shimadzu multipurpose recording spectrophotometer MPS-2000 (Shimadzu, Kyoto, Japan) equipped with graphic printer PR-3.

HPLC analyses were run on a Waters system (Waters, Milford, MA, USA) equipped with flow controller 600, autosampler 717 and UV detector 486 (Waters). Data were processed with Millennium 32 software (Waters).

\footnotetext{
${ }^{1}$ Institute of Microbiology, Academy of Sciences of the Czech Republic v.v.i., Prague, Czech Republic; ${ }^{2}$ Institute of Molecular Genetics and Genetic Engineering, University of Belgrade, Belgrade, Serbia; ${ }^{3}$ Department of Cell Biology, Faculty of Science, Charles University, Prague, Czech Republic and ${ }^{4}$ Institute of Molecular Genetics, Academy of Sciences of the Czech Republic v.v.i., Prague, Czech Republic

Correspondence: Dr M Flieger, Institute of Microbiology, Academy of Sciences of the Czech Republic v.v.i., 14220 Prague 4, Czech Republic.

E-mail: flieger@biomed.cas.cz

Received 15 February 2011; revised 25 July 2011; accepted 28 July 2011; published online 14 September 2011
} 
Specimens prepared from the biological activity assays were imaged and images were processed using the Olympus IX-81 Cell microscope (Olympus Czech Group, Prague, Czech Republic) equipped with Hamamatsu C4742-8012AG digital camera (Hamamatsu Photonics, Hamamatsu, Japan).

Optical rotation was measured on AUTOPOL IV polarimeter (Rudolph Research Analytical, Hackettstown, NJ, USA). $[\alpha]_{\mathrm{D}}^{20}-33.2$ (c 0.6, MeOH).

\section{Fermentation}

The stock cultures of S. durmitorensis sp. nov., type strain MS405 (DSM41863T; wild type $)^{23,24}$ and the mutant strain named as A10 were maintained at $30^{\circ} \mathrm{C}$ on petri dishes containing NE medium ( $1 \%$ glucose, $0.2 \%$ yeast extract, $0.1 \%$ beef extract, $0.2 \%$ casamino acids and $2 \%$ agar; $\mathrm{pH}=7.0$ ). The seed culture was made by inoculation of $5 \mathrm{ml} \mathrm{NE}$ liquid medium with completely dry white to gray colored colonies with high production of spores, and the growth was performed for 14 days at $28^{\circ} \mathrm{C}$ in the dark on a rotary shaker (200 r.p.m.). The seed culture $(5 \mathrm{ml})$ was inoculated into the fermentation (Tryptic Soy Broth; Difco Detroit, MI, USA; 3\% Triptic Soy Broth Powder supplemented with 10\% mannitol) medium using $500 \mathrm{ml}$ flasks and the same cultivation conditions as mentioned above.

\section{Extraction and isolation}

Harvested broth (1.61) of $S$. durmitorensis was centrifugated (12000 r.p.m.; $20 \mathrm{~min} ; 22^{\circ} \mathrm{C}$ ), filtered and obtained supernatant was passed through SPE cartridge (STRATA C18-E; giga tubes $20 \mathrm{~g}$ per $60 \mathrm{ml}, 55 \mu \mathrm{m}$, 70 A; Phenomenex, Chromservis, Prague, Czech Republic) first conditioned with $\mathrm{MeOH}(100 \mathrm{ml})$ and subsequently with $\mathrm{H}_{2} \mathrm{O}(100 \mathrm{ml})$. After application of supernatant $(150 \mathrm{ml})$, followed by washing step $\left(3 \times 100 \mathrm{ml}\right.$ of $\left.\mathrm{H}_{2} \mathrm{O}\right)$, the compounds were eluted with stepwise $\mathrm{MeOH}$ gradient (from 10 to $90 \%$; each step $100 \mathrm{ml}$ ). Collected fractions were evaporated to dryness, frozen or immediately reconstituted in $\mathrm{MeOH}$. Bioactivity assay was carried out by the same procedure as published previously. ${ }^{25}$ Active fractions ( 80 and 90\%) were applied on HPLC analysis for further purification and characterization. Mycelium (175 g of wet biomass containing mainly spores and cell debris) was collected from fermentation broth of $S$. durmitorensis after centrifugation, followed by three times extraction with EtOAc. The pooled extracts were evaporated to dryness under reduced pressure and disolved in $\mathrm{MeOH}$. Semi-preparative HPLC analyses were carried out on Discovery BIO Wide Pore C18 column $(10 \mathrm{~mm} \times 150 \mathrm{~mm} ; 10 \mu \mathrm{m}$; Supelco, Sigma-Aldrich, St Louis, MO, USA) with a mobile phase A $(5 \% \mathrm{MeOH}$ in $\mathrm{H}_{2} \mathrm{O}$ ) and $\mathrm{B}(\mathrm{MeOH})$. Gradient elution started at $100 \% \mathrm{~A}(0 \mathrm{~min})$, increasing linearly to $100 \%$ B within $45 \mathrm{~min}$, followed by column washing step (100\% B, $10 \mathrm{~min})$, and equilibration step (100\% A, $15 \mathrm{~min})$ at flow rate $1.5 \mathrm{ml} \mathrm{min}^{-1}$; UV detection at $360 \mathrm{~nm}$; column temperature, $35^{\circ} \mathrm{C}$. The collected fractions maintained in dark were pooled, evaporated to dryness under reduced pressure and stored at $-20{ }^{\circ} \mathrm{C}$.

\section{Mass spectrometry}

The isolated HPLC fraction and the crude EtOAc extract of the mycelia were dissolved in $\mathrm{MeOH} / \mathrm{H}_{2} \mathrm{O}$ (50:50) and analyzed by direct infusion on an APEXUltra FTMS instrument equipped with a 9.4 T. Superconducting magnet and a Dual II ion source (Bruker Daltonics, Billerica, MA, USA). The analysis was performed using electrospray ionization and the spectra were acquired in both positive and negative ion mode. The cell was opened for $1.3 \mathrm{~ms}$, accumulation time was set at $0.2 \mathrm{~s}$ for MS experiment ( $1.0 \mathrm{~s}$ for MS/MS experiment), and one experiment consisting of the average of eight spectra was collected for each sample. After MS one MS/MS experiment was performed from the desired ion. The isolation window was set 4 a.m.u. and the collision energy was maintained at $-24 \mathrm{~V}$ (positive mode) and $16 \mathrm{~V}$ (negative mode). The acquisition data set size was set to $1 \mathrm{M}$ points with the mass range starting at $\mathrm{m} / \mathrm{z} 150$ a.m.u., resulting in a resolution of $100000 \mathrm{at} \mathrm{m} / \mathrm{z} 400$. The instrument was externally calibrated using clusters of arginine resulting in mass accuracy below 2 p.p.m. The acquired spectra were apodized with a square sine bell function and Fourier transformed with one zero-fill. The interpretation of mass spectra was carried out using DataAnalysis version 4.0 software package (Bruker Daltonics).

\section{NMR spectroscopy}

NMR spectra were recorded on a Bruker Avance III $\left(600.23 \mathrm{MHz}\right.$. for ${ }^{1} \mathrm{H}$, 150.94 MHz for ${ }^{13} \mathrm{C}$, Bruker BioSpin $\mathrm{GmbH}$, Rheinstetten, Germany) in $\mathrm{CD}_{3} \mathrm{OD}$ at $303 \mathrm{~K}$. The residual solvent signal was used as an internal standard $\left(\delta_{\mathrm{H}}\right.$ 3.330 p.p.m., $\delta_{\mathrm{C}} 49.30$ p.p.m.). ${ }^{1} \mathrm{H}$ NMR, ${ }^{13} \mathrm{C}$ NMR, gCOSY, ${ }^{1} \mathrm{H}_{-}{ }^{13} \mathrm{C}$ gHSQC, ${ }^{1} \mathrm{H}_{-}{ }^{13} \mathrm{C}$ gHMBC, ROESY and 1D-TOCSY spectra were measured using standard manufacturers' software. ${ }^{1} \mathrm{H}$ NMR spectrum was zero filled to fourfold data points and multiplied by a window function (two-parameter double-exponential Lorentz-Gauss function) before Fourier transformation to improve the resolution. ${ }^{13} \mathrm{C}$ NMR spectrum was zero filled to twofold data points. Then the line broadening $(1 \mathrm{~Hz})$ was used to improve the signal to noise ratio. Protons were assigned by COSY and the assignment was transferred to carbons by HSQC. Chemical shifts are given in $\delta$ scale (p.p.m.), coupling constants are given in $\mathrm{Hz}$.

\section{Bioactivity assays on carcinoma cell lines}

All carcinoma cell lines were purchased from the American Type Culture Collection (Manassas, VA, USA). Cell lines HL-60 (human promyelocytic leukemia), 4T1 (mouse mammary carcinoma) and CT26.CL25 (mouse colon carcinoma) were maintained at exponential growth in RPMI 1640 medium, HeLa (human cervical carcinoma) and A431 (human epidermoid carcinoma) in Dulbecco's modified Eagle's medium, and MDA-MB-231 (human breast carcinoma) in Leibovitz's L-15 medium with $2 \mathrm{~mm}$ L-glutamine, $10 \mathrm{~mm}$ 4-(2hydroxyethylpiperazine-1-ethanesulfonic acid, $0.45 \%$ glucose, $100 \mathrm{U} \mathrm{ml}^{-1}$ penicillin, $50 \mu \mathrm{g} \mathrm{m}^{-1}$ streptomycin, $1 \mathrm{~mm}$ sodium pyruvate and $10 \%$ fetal calf serum. Cells were maintained at $37^{\circ} \mathrm{C}$ in a humidified $5 \% \mathrm{CO}_{2}$ atmosphere. For in vitro toxicity and cell death experiments, $1-1.5 \times 10^{5}$ cells were seeded in $1.8 \mathrm{~cm}^{2}$ well and next day various concentrations of component $1(10-100 \mu \mathrm{M})$ were added to the cultivation media. The cell mortality of treated cultures was determined by the Trypan blue exclusion method after 12, 24 and $48 \mathrm{~h}$. Control experiments were performed in parallel with addition of dimethyl sulfoxide solvent only.

DNA fragmentation was determined in DDHR-treated HL-60 cells. Cells were harvested by centrifugation ( $700 \mathrm{~g}$ for $5 \mathrm{~min}$ ), incubated with $0.5 \mathrm{ml}$ extraction buffer (10 mM TRIS, $0.1 \mathrm{~mm}$ EDTA and $0.5 \%$ SDS) containing RNase $\left(10 \mu \mathrm{g} \mathrm{ml}^{-1}\right)$ at $37^{\circ} \mathrm{C}$ for $1 \mathrm{~h}$ and digested with proteinase $\mathrm{K}$ (final concentration $300 \mu \mathrm{g} \mathrm{ml}^{-1}$ ) for $2 \mathrm{~h}$ at $50{ }^{\circ} \mathrm{C}$. The DNA was then extracted with phenol/ chloroform mixture (1:1), precipitated with ethanol and analyzed by $1.5 \%$ agarose gel electrophoresis for $3.5 \mathrm{~h}(2 \mathrm{~V} / \mathrm{cm}$ gradient). GeneRuler Express DNA Ladder (Fermentas, St Leon-Rot, Germany) was used to size the DNA fragments. The gel was stained with ethidium bromide and the DNA bands were viewed under $312 \mathrm{~nm}$ light.

\section{Bioactivity assays on HeLa cells}

Cells were cultivated in D-MEM medium supplemented with $10 \%$ fetal calf serum (Gibco, Invitrogen, Carlsbad, CA, USA) grown on the glass cover slips (up to $50 \%$ density) in 6-well plates (Nunc, Thermo Fisher Scientific, Waltham, MA, USA), treated with DDHR dissolved in dimethyl sulfoxide (stock solution $10 \mathrm{mM}$ ) for various times and concentrations. Wells containing dimethyl sulfoxide only (maxmimum 1\%) were assayed as a blank control-no alteration of cellular morphology and physiology was observed. All samples were tested in triplicates. Treated cells (various times and concentrations) grown at $37^{\circ} \mathrm{C}$ in a humidified $5 \% \mathrm{CO}_{2}$ atmosphere were fixed (3.7\% paraformaldehyde in phosphate-buffered saline, $20 \mathrm{~min}$, room temperature), permeabilized $(0.1 \%$ Triton X-100 in phosphate-buffered saline), blocked ( $1 \%$ bovine serum albumin in phosphatebuffered saline) and stained with Phalloidin-Alexa567 or Phalloidin-Alexa488, anti-tubulin antibody (TUB-1, Exbio, Vestec, Czech Republic) followed by secondary GAM-Alexa488 or anti-Lamp-1 antibody (Santa Cruz Biotechnology, Santa Cruz, CA, USA), followed by secondary GAM-Alexa594 antibody. Staining of the nuclei was performed mounting specimens in Mowiol-DAPI. DDHRbased fluorescent labeling was performed on fixed cells (3.7\% paraformaldehyde in phosphate-buffered saline, $20 \mathrm{~min}$, room temperature) without permeabilization (1 h, room temperature). All fluorescent reagents (including secondary antibodies) were purchased from Molecular Probes, Invitrogen.

\section{RESULTS AND DISCUSSION}

\section{Fermentation and isolation of active compound}

During screening of soil samples collected in the area of the Durmitor National Park, Serbia and Montenegro we isolated and identified the actinomycete $S$. durmitorensis sp. nov., type strain MS405 


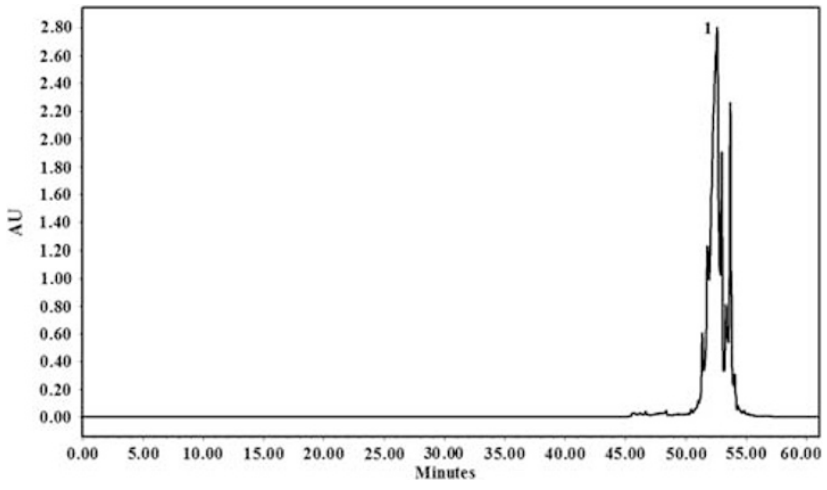

Figure 1 HPLC chromatogram of the crude EtOAc extract of the Streptomyces durmitorensis sp. nov., type strain MS405 mycelia. Chromatographic conditions: column, Discovery BIO Wide Pore C18 (Supelco), $150 \times 10 \mathrm{~mm} I \mathrm{D}$; particle size $10 \mu \mathrm{m}$; mobile phase A $(5 \% \mathrm{MeOH}$ in $\left.\mathrm{H}_{2} \mathrm{O}\right)$ and $\mathrm{B}(\mathrm{MeOH})$. Gradient elution, $100 \% \mathrm{~A}(\mathrm{O} \mathrm{min})$ increasing linearly to $100 \%$ B within $45 \mathrm{~min}$, followed by column washing step $(100 \% \mathrm{~B}$, $10 \mathrm{~min})$, and equilibration step ( $100 \% \mathrm{~A}, 15 \mathrm{~min})$; flow rate $1.5 \mathrm{ml} \mathrm{min}-1$; UV detection, $360 \mathrm{~nm}$; column temperature, $35^{\circ} \mathrm{C}$.

(DSM41863T; wild type). ${ }^{23}$ Using bioactivity assay ${ }^{25}$ on immunosuppressant-sensitive Saccharomyces cerevisiae FAV20 strain we found that this isolate produces compound(s) with a similar mechanism of action like immunosuppressant FK506. The disruption of the gene for the $\beta$-keto-synthase domain of the thiostrepton-resistant transformant of S. durmitorensis mutant strain A10 completely abolished the production of the active compounds. The presence of the inactivation cassette in this strain was also confirmed by Southern blot analysis using $t s r$ gene as a probe (data not shown). This experiment confirmed that the modular polyketide synthase is responsible for the production of bioactive compound.

Time-dependent production of active compound was investigated in both $S$. durmitorensis strains as a function of $\mathrm{CFU} \mathrm{ml}{ }^{-1}$ over time and monitored in a bioassay on FK506-sensitive yeast strain S. cerevisiae FAV20. Only the wild-type strain MS405 produced active metabolite upon reaching the stationary phase $(72 \mathrm{~h})$ in contrary to the mutant strain A10 (data not shown).

To purify the active compound(s) the culture supernatant $(150 \mathrm{ml})$ of wild-type S. durmitorensis was loaded on SPE cartridge and eluted with stepwise gradient of $\mathrm{MeOH}$ in water (10-100\%). Obtained 10 fractions and crude EtOAc extracts $(1.5 \mathrm{~g})$ prepared from wet mycelia cake ( $175 \mathrm{~g}$ ) were tested for bioactivity on FK506-sensitive yeast strain S. cerevisiae FAV20. The crude EtOAc extract and fractions eluted with 80 and $90 \%$ of $\mathrm{MeOH}$ were found to contain the bioactive compound.

Further HPLC purification was carried out using the Discovery BIO Wide Pore C18 column. Out of the several mobile phases tested (different buffers and organic modifiers) the mobile phase consisting of $\mathrm{MeOH}$-water was selected for further compound purification because of the lowest degree of decomposition observed. It could be seen from the presented chromatogram (Figure 1) that under these conditions only partial separation of about seven closely related compounds was reached. The described procedure allows us to isolate the major active component $\mathbf{1}$ in sufficient quantity and quality for further structure determination by UV, MS/MS and NMR spectrometry.

\section{Structure elucidation}

The combined fractions of semipreparative runs containing active major component $\mathbf{1}$ were evaporated to dryness under reduces

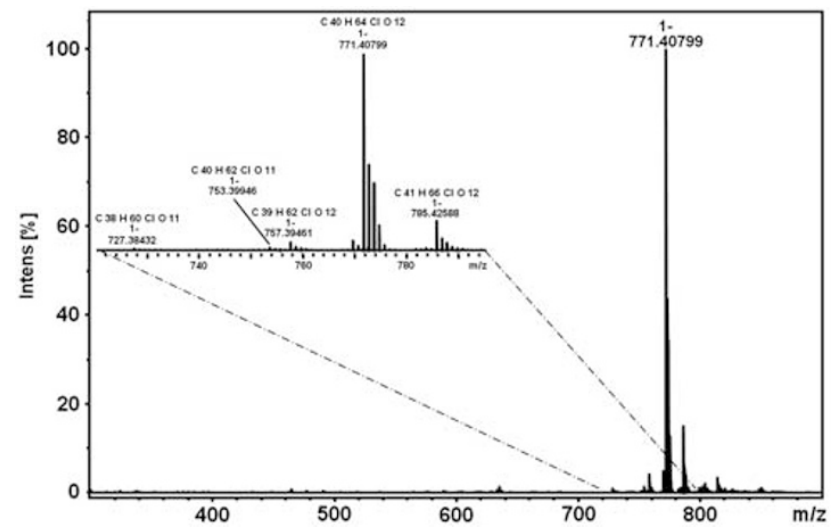

Figure 2 Negative ion mode FTMS spectrum of the crude EtOAc extract of the Streptomyces durmitorensis sp. nov., type strain MS405 mycelia. All substances were observed as chlorinated adduct ions.

Table 1 The polyene macrolides identified in mycelial crude extract of Streptomyces durmitorensis sp. nov., type strain MS405 (DSM41863T; wild type). Elemental composition, relative abundance, experimental and theoretical masses, mass errors, and suggested structural differences are shown

\begin{tabular}{lcccc}
\hline $\begin{array}{l}\text { Formula } \\
\text { (abundance \%) }\end{array}$ & $\begin{array}{c}\text { Experimental } \\
\text { mass }\end{array}$ & $\begin{array}{c}\text { Theoretical } \\
\text { mass }\end{array}$ & Error & Annotation \\
\hline $\mathrm{C}_{38} \mathrm{H}_{60} \mathrm{O}_{11}$ (1) & 692.41392 & 692.41356 & 0.5 p.p.m. & $-\mathrm{C}_{2} \mathrm{H}_{4} \mathrm{O}$ \\
$\mathrm{C}_{39} \mathrm{H}_{62} \mathrm{O}_{12}$ (4) & 722.42489 & 722.42413 & 1.0 p.p.m. & $-\mathrm{CH}_{2}$ \\
$\mathrm{C}_{40} \mathrm{H}_{62} \mathrm{O}_{11}$ (1.5) & 718.43001 & 718.42921 & 1.1 p.p.m. & $-\mathrm{H}_{2} \mathrm{O}$ \\
$\mathrm{C}_{40} \mathrm{H}_{64} \mathrm{O}_{12}(100)$ & 736.44049 & 736.43978 & 1.0 p.p.m. & DDHR (1) \\
$\mathrm{C}_{41} \mathrm{H}_{66} \mathrm{O}_{12}$ (15) & 750.45608 & 750.45543 & 0.9 p.p.m. & $+\mathrm{CH}_{2}$ \\
\hline
\end{tabular}

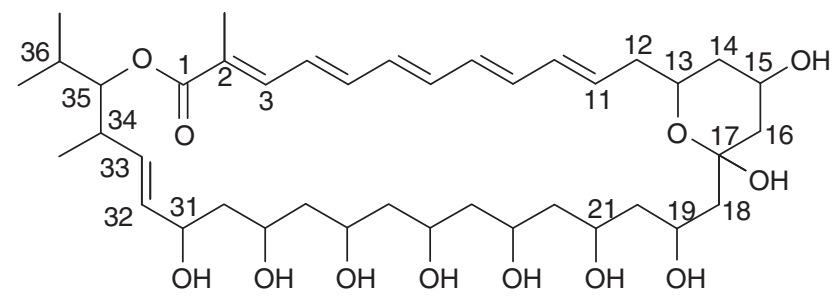

Figure 3 Structure of 32,33-didehydroroflamycoin component $\mathbf{1}$.

pressure. The resulting yellow amorphous powder was soluble in $\mathrm{MeOH}, \mathrm{EtOH}, \mathrm{Me}_{2} \mathrm{CO}$ and dimethyl sulfoxide, but insoluble in water. The UV-VIS spectra in $\mathrm{MeOH}$ showed characteristic absorption maxima for polyene macrolide; a broad UV absorption band in the range $243-275 \mathrm{~nm}$ with maxima $260 \mathrm{~nm}$ and strong UV absorption maxima at $363 \mathrm{~nm}$ with a shoulder at $375 \mathrm{~nm}$, thus suggesting the presence of a conjugated pentaene part.

Mass spectrometric analysis of active fraction in positive ion mode revealed sodium and potassium adduct ions at $\mathrm{m} / \mathrm{z} 759.42891$ and 775.40317 corresponding to elemental composition $\mathrm{C}_{40} \mathrm{H}_{64} \mathrm{O}_{12}$ within mass accuracy 0.1 and 0.3 p.p.m., respectively. Also, an extensive family of relating ions with water losses (from one up to nine) was observed. The search for compounds of related composition retrieved roflamycoin containing two more hydrogens in the molecule. ${ }^{18,19}$ The MS/MS experiment of the sodium adduct ion at $\mathrm{m} / \mathrm{z} 759.42891$ 
Table $2{ }^{1} \mathrm{H}$ and ${ }^{13} \mathrm{C}$ NMR data of component 1 (600.23 and $150.94 \mathrm{MHz}$ for ${ }^{1} \mathrm{H}$ and ${ }^{13} \mathrm{C}$, respectively, $\left.\mathrm{CD}_{3} \mathrm{OD}, 30{ }^{\circ} \mathrm{C}\right)$

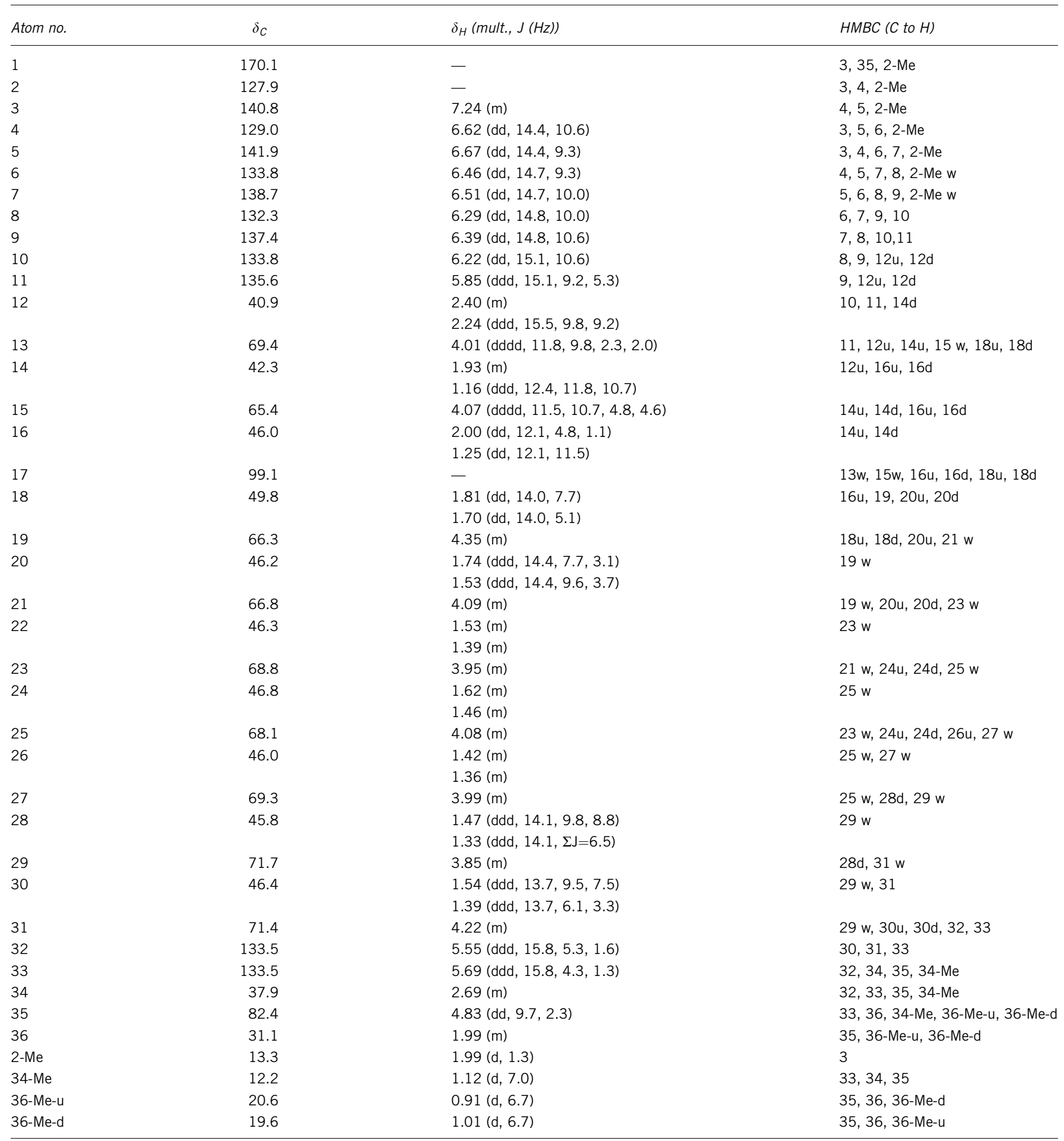

Abbreviations: d, downfield; HSQC readout; mult., multiplicity; u, upfield; w, weak.

resulted in the prediction of DDHR structure. The analysis was performed in negative ion mode as well. In the negative ion mode only the $\left(\mathrm{M}-\mathrm{H}^{+}\right)^{-}$and $\left(\mathrm{M}+\mathrm{Cl}^{-}\right)^{-}$ions of component 1 were observed. There was no evidence for dehydrated forms of the polyene macrolide. The MS/MS experiments of deprotonated ion at $\mathrm{m} / \mathrm{z}$ 735.43295 and chlorine adduct ion at $\mathrm{m} / \mathrm{z} 771.41001$ confirmed the structure of the active substance. Finally, the crude extract was analyzed in negative ion mode in terms to characterize other substances produced. Several macrolides structurally related to component 1 were detected (Figure 2, Table 1).

The structure of component $\mathbf{1}$ (Figure 3 ) was elucidated by extensive NMR studies. The complete assignment of all proton and 
Table 3 Concentrations of component 1 required for $50 \%$ inhibition of the cell viability in various tumor cell lines after $48 \mathrm{~h}$ treatment

\begin{tabular}{lc}
\hline Cell line & $I C_{50}(\mu \mathrm{M}) \pm$ s.d. \\
\hline HL60 (human promyelocytic leukemia) & $60 \pm 5$ \\
4T1 (mouse mammary carcinoma) & $75 \pm 10$ \\
A431 (human epidermoid carcinoma) & $80 \pm 4$ \\
CT26 (mouse colon carcinoma) & $95 \pm 12$ \\
MDA-MB-231 (human breast carcinoma) & $65 \pm 5$ \\
HeLa (human cervical carcinoma) & $100 \pm 15$ \\
\hline
\end{tabular}

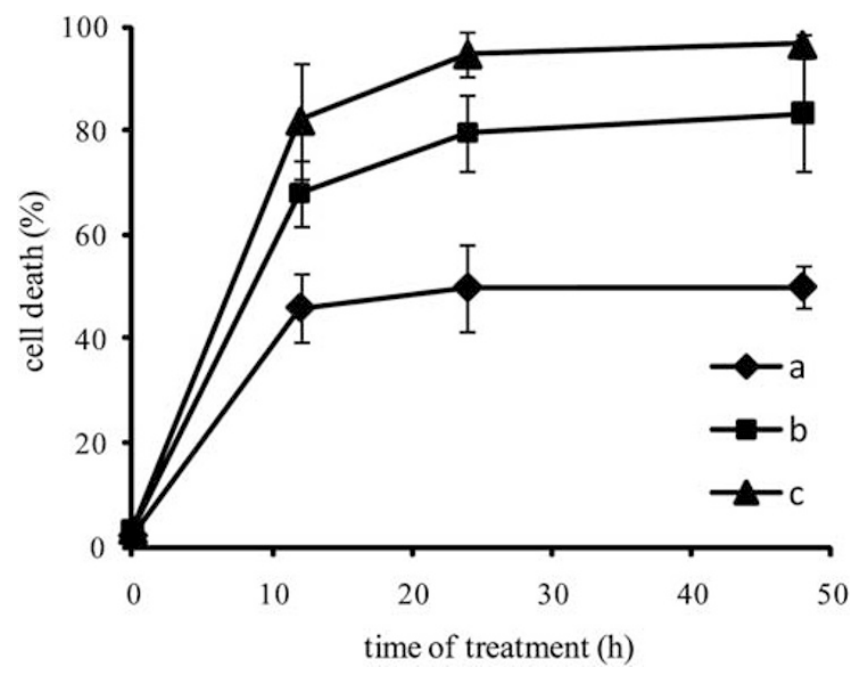

Figure 4 Toxicity of component 1 (DDHR) against HL60 cells. Cells were incubated with various concentrations of component $1(a=60 \mu \mathrm{m}, b=70 \mu \mathrm{m}$, and $\mathrm{c}=80 \mu \mathrm{m}$ ) and cell death was determined after 12,24 and $48 \mathrm{~h}$ by trypan blue exclusion method. The averages for three independent experiments are shown with s.d.s.

carbon resonances listed in Table 2 was achieved using various 2D NMR techniques including COSY, HSQC, HMBC, ROESY and 1D TOCSY experiments.

The ${ }^{13} \mathrm{C}$ NMR spectrum contains 39 signals, which in fact represent 40 carbons due to an overlap of two carbons identified by HSQC. Their multiplicity was sorted by combination of multiplicity-edited HSQC and HMBC spectra. A total of $4 \mathrm{Me}, 10$ methylenes, 23 methines (11 sp $p^{2}$ - and $2 s p^{3}$ hybridized and 10 oxymethines) and 3 quaternary carbons were distinguished. The ${ }^{1} \mathrm{H}$ NMR spectrum contains three secondary $\mathrm{Me}$ (doublets at 0.911, 1.009 and 1.122 p.p.m.), olefinic $\mathrm{Me}$ at 1.993 p.p.m. together with numerous methylenes, oximethines and olefinic protons.

A detailed analysis of the homonuclear and heteronuclear 2D NMR spectra allowed us to identify two main fragments (A and B). The fragment A was deduced as follows. When tracing the COSY correlations starting from methine $\mathrm{H}-3$ at 7.243 p.p.m., a continuous sequence of signals could be followed within structural part A to a terminal aliphatic methylene group resonating at 2.003 and 1.250 p.p.m. The part A can be further extended due to long-range COSY correlation to the methyl 2-Me (1.993 p.p.m.), which indicates that the $\Delta^{1,2}$ double bond is substituted by the methyl group. The HMBC correlation of $\mathrm{H}-15$ and $\mathrm{H}-16$ protons to the carbon signal at 99.13 p.p.m. indicates a quaternary carbon at the end of the fragment

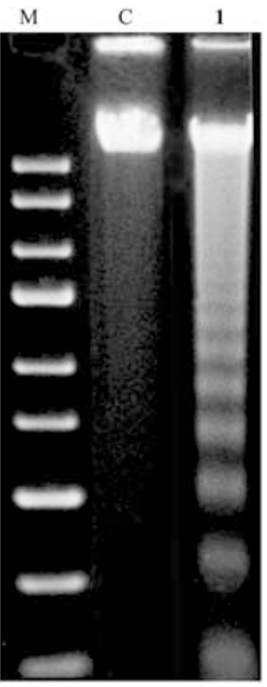

Figure 5 DNA fragmentation in HL60 cells treated with component 1 (DDHR). Cells exposed to $50 \mu \mathrm{m}$ of component 1 were harvested after $4 \mathrm{~h}$ and isolated DNA was analyzed by $1.5 \%$ agarose gel electrophoresis. Control cells $(\mathrm{C})$ were treated with dimethyl sulfoxide only. M, DNA marker.
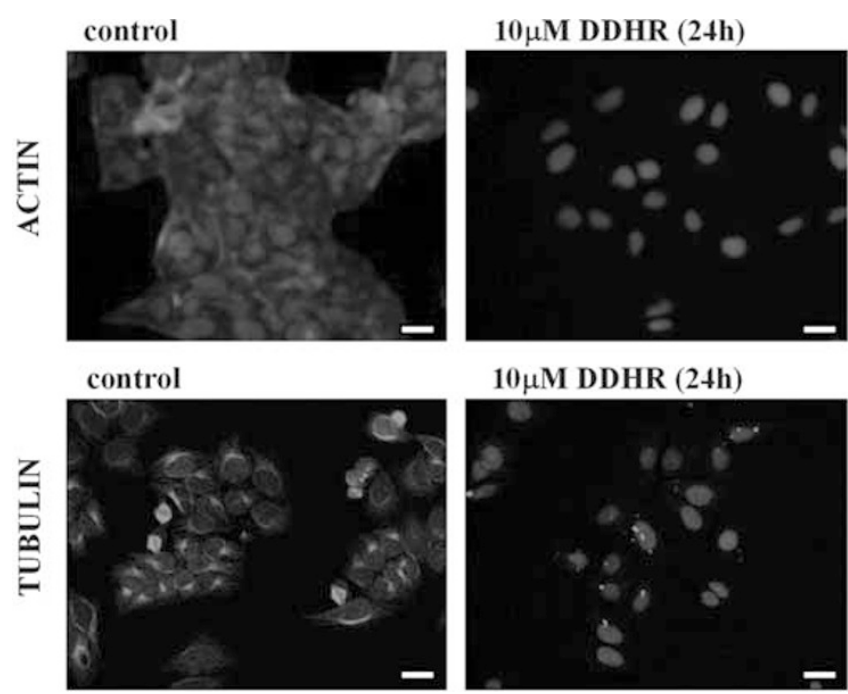

$10 \mu \mathrm{M}$ DDHR $(2+\mathrm{h})$

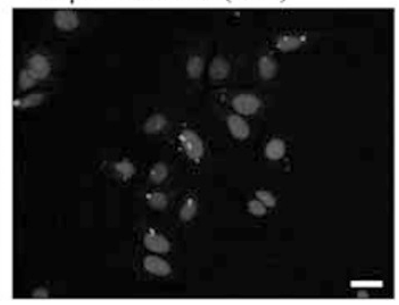

Figure 6 Alteration of the actin and tubulin cytoskeleton in HeLa cells treated with $10 \mu \mathrm{m}$. DDHR for $24 \mathrm{~h}$. Blue, nuclei stained with DAPI; red, F-actin stained with Phalloidin-Alexa594, green, tubulin stained with the anti-tubulin monoclonal antibody. Scale bar $20 \mu \mathrm{m}$. A full color version of this figure is available at The Journal of Antibiotics journal online.

A. The heteronuclear long-range coupling between H-13 and C-17 allowed closing the terahydropyrane moiety. The coupling pattern of the proton signals $\mathrm{H}-13$ and $\mathrm{H}-15$ indicated their axial orientation. The configuration of the double bonds in the fragment $\mathrm{A}$ can be derived from vicinal coupling constants. Their values are around $15 \mathrm{~Hz}$, which indicates $E$ configuration of the $\Delta^{4,5}, \Delta^{6,7}, \Delta^{8,9}$ and $\Delta^{10,11}$ double bonds. The configuration on the remaining $\Delta^{1,2}$ double bond was derived from the ROESY spectrum. The detected correlation between 2-Me and $\mathrm{H}-4$ is consistent with $E$ configuration.

The structure elucidation of the part $\mathrm{B}$ originated from the oxymethine proton $\mathrm{H}-35\left(\delta_{\mathrm{H}} 4.831\right)$ in two directions. It has correlation with a methine $\mathrm{H}-36$, which is further coupled to two methyls 


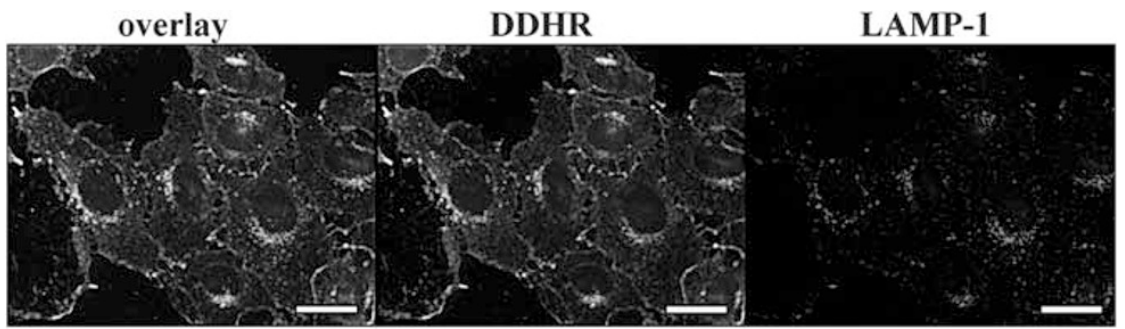

Figure 7 Labeling of PFA-fixed HeLa cells with component 1 (DDHR, $1 \mathrm{~h}, 300 \mu \mathrm{m}$ ), co-localization of the DDHR-positive vesicles with the late endosomal/ lysosomal marker Lamp-1. Red, typical distribution of the late endosomes/lysosomes stained with anti-LAMP-1 antibody; white, fluorescent signal of DDHR localized at the membrane and in the distinct foci highly co-localizing with the Lamp-1 signal. Scale bar $10 \mu \mathrm{m}$. A full color version of this figure is available at The Journal of Antibiotics journal online.

(doublets at 0.911 and 1.009 p.p.m.). The chain of the part B can be extended in the opposite direction through the observation of strong vicinal COSY correlation to the aliphatic methine proton at 2.691 p.p.m. The COSY spectrum allowed to identify the fragment from $\mathrm{H}-34$ to $\mathrm{H}-27$ and $\mathrm{H}-21$ to $\mathrm{H}-18$. The remaining part was derived from the HMBC correlations. The coupling constant ${ }^{3} J_{\mathrm{H}-32, \mathrm{H}-33}=15.8 \mathrm{~Hz}$ indicated their $E$ configuration.

Protons H-19, and H-18 has HMBC contact with C-16, which connected fragment $\mathrm{B}$ to the fragment $\mathrm{A}$. The correlation between $\mathrm{H}-35$ and $\mathrm{C}-1$ revealed the lactone ring closure.

\section{Biological activity}

Compound 1 (DDHR) induces cell death in various cancer cell lines with slightly different effectivity as demonstrated by the range of $\mathrm{IC}_{50}$ (Table 3). The toxicity toward cancer cells was dose dependent and increased with incubation time, but the progression was not linear as most of the cell killing occurred within $12 \mathrm{~h}$ (Figure 4). The prevalent mode of DDHR induced cell death was apoptosis as demonstrated by DNA fragmentation (Figure 5).

Biological activity assay performed on HeLa cells shows dramatic modulation of the cellular physiology. Concentrations $>25 \mu \mathrm{m}$ had a cytotoxic effect, cells detached and became permeable for dyes, indicating dead or terminally apoptotic cells (DAPI). Treatment of HeLa cells with component $1(10 \mu \mathrm{M}, 24 \mathrm{~h})$ resulted in complete loss of F-actin (visualized using fluorescently labeled phalloidin) and transformation of microtubular cytoskeleton into distinct speckles (Figure 6). Staining of the HeLa cells with component 1 after fixation with PFA could be followed by the permeabilization and antibody staining, allowing us to identify the nature of the DDHR-positive internal vesicles as Lamp-1-positive ones (late endosomes and lysosomes; Figure 7). Component 1 obviously quickly entered the cellular interior through membrane flow and vesicular trafficking. This feature together with internal fluorescence could be used for direct visualization of uptake and cellular localization after in vivo treatment and in fixed cells.

\section{ACKNOWLEDGEMENTS}

We thanks the Institutional Research Concept AV 0 Z502 00510, Center of Molecular and Cellular Immunology 1M6837805001 nda MSM0021620858, grant no. 2B08064 of the Ministry of Education Youth and Sport, grant no. 143056 of the Ministry of Science of the Republic of Serbia and Bilateral cooperation project between Serbian Academy of Sciences and Academy of Sciences of the Czech Republic for their financial contribution.
1 Hill, L. T. \& Fenical, W. Pharmaceuticals from marine natural products: surge or ebb? Curr. Opini. Biotechnol. 21, 777-779 (2010).

2 Blunt, J. W., Coop, B. R., Munro, M. H. G., Northcote, P. T. \& Prinsep, M. R. Marine natural products. Nat. Prod. Rep. 27, 165-237 (2010).

3 Blunt, J. W. et al. Marine natural products. Nat. Prod. Rep. 26, 170-244 (2009).

4 Berdy, J. Bioactive microbial metabolites: a personal view. J. Antibiot. 58, 1-26 (2005).

5 Staunton, J. \& Weissman, K. J. Polyketide biosynthesis: a millennium review. Nat. Prod. Rep. 18, 380-416 (2001).

6 Omura, S. \& Tanaka, H. Production and antimicrobial activity of macrolides. In Macrolide antibiotics: chemistry, biology and practice (ed. Omura, S.) 1-19 Academic Press ISBN 0-12-526450-X., Orlando, Fla, (1984).

7 Findlay, J. A. \& Radics, L. On the chemistry and high field nuclear magnetic resonance spectroscopy of rapamycin. Can. J. Chem. 58, 579-590 (1980).

8 McGarvey, G. J., Mathys, J. A. \& Wilson, K. J. Synthesis of amphotericin B. A convergent strategy to the polyol segment of the heptaene macrolide antibiotics. J. Org. Chem. 61, 5704-5705 (1996).

9 Pandey, R. C. \& Rinehart, K. L Jr Polyene antibiotics. V. Characterization of components of the filipin complex by mass spectrometry. J. Antibiot. 23, 414-417 (1970).

$10 \mathrm{Holz}, \mathrm{R}$. W. Polyene antibiotics: nystatin, amphotericin B and filipin. In Antibiotics 5, (ed. Hahn, F. E.) 313-340 Springer-Verlag, New York, (1979).

11 Caffrey, P., Aparicio, J. F., Malpartida, F. \& Zotchev, S. B. Biosynthetic Engineering of polyene macrolides towards generation of improved antifungal and antiparasitic agents. Curr. Topics Med. Chem. 8, 639-653 (2008).

12 Bruheim, P. et al. Chemical diversity of polyene macrolides produced by Streptomyces noursei ATTC 11455 and recombinant strain ERD44 with genetically altered polyketide synthase NysC. Antimicrob. Agents Chemother. 48, 4120-4129 (2004).

13 Kwon, H. C., Kauffman, C. A., Jensen, P. R. \& Fenical, W. Marinisporolides, polyenepolyol macrolides from marine actinomycete of the new genus Marinispora. J. Org. Chem. 74, 675-684 (2009).

14 Xiang, W- S., Wang, J- D., Wang, X- J. \& Zhang, J. A novel macrolide compound from Streptomyces bingchenggensis: fermentation, isolation, structure elucidation and biological properties. J. Antibiot. 62, 229-231 (2009).

15 Kozone, I. et al. Novel 24-membered macrolides JBIR-19 and -20 isolated from Metarhizium sp. fE61. J. Antibiot. 62, 159-162 (2009).

16 Schlegel, R. \& Thrum, H. A new polyene antibiotic, flavomycoin. Structural investigations. I. J. Antibiot. 24, 360-374 (1971).

17 Schlegel, R., Thrum, H., Zielinski, J. \& Borowski, E. The structure of roflamycoin, a new polyene macrolide antifungal antibiotic. J. Antibiot. 34, 122-123 (1981).

18 Rychnovsky, S. D., Griesgraber, G. \& Schlegel, R. Stereochemical determination of roflamycoin: 13C acetonide analysis and synthetic correlation. J. Am. Chem. Soc. 117, 197-210 (1995).

19 Rychnovsky, S. D., Khire, U. R. \& Yang, G. Total synthesis of the polyene macrolide roflamycoin. J. Am. Chem. Soc. 119, 2058-2059 (1997).

20 Grigorjev, P. A. \& Bezrukov, S. M. Hofmeister effect in ion transport: reversible binding of halide anions to the roflamycoin channel. Biophys. J. 67, 2265-2271 (1994).

21 Bolard, J. How do the polyene macrolide antibiotics affect the cellular membrane properties? Biochim. Biophys. Acta 864, 257-304 (1986).

22 Zotchev, S. B. Polyene macrolide antibiotics and their applications in human therapy. Curr. Med. Chem. 10, 211-223 (2003).

23 Savic, M., Bratic, I. \& Vasiljevic, B. Streptomyces durmitorensis sp. nov., a producer of an FK506-like immunosuppressant. Int. J. Syst. Evol. Microbiol. 57, 2119-2124 (2007).

24 Savic, M. \& Vasiljevic, B. Targeting polyketide synthase gene pool within actinomycetes: new degenerate primers. J. Ind. Microbiol. Biotechnol. 33, 423-430 (2006).

25 Skoko, N. et al. Construction of Saccharomyces cerevisiae strain FAV20 useful in detection of immunosuppressants produced by soil actinomycetes. J. Microbiol. Methods 61, 137-140 (2005). 